\title{
PEMANFAATAN TEKNOLOGI PRESENSI UNTUK APARATUR DESA PADA DESA BAYURLOR
}

\author{
Anis Fitri Nur Masruriyah', Muhammad Baharudin ${ }^{2}$ \\ Teknik Informatika \\ Fakultas Teknik dan Ilmu Komputer \\ Universitas Buana Perjuangan Karawang anis.masruriyah@ubpkarawang.ac.id ${ }^{1}$ \\ if16.muhamadbaharudin@mhs.ubpkarawang.ac.id ${ }^{2}$
}

\begin{abstract}
Abstrak
Pada era modern seperti saat ini, ternyata masih banyak instansi yang belum memaksimalkan teknologi. Salah satu contoh teknologi yang belum banyak digunakan di beberapa instansi yaitu sistem presensi. Saat ini masih ada presensi yang mengandalkan tanda tangan absen tanpa ada keterangan waktu datang dan pulang. Hal ini berdampak pada kinerja suatu instansi, terlebih instansi yang melakukan pelayanan publik. Tidak jarang ditemui instansi yang karyawannya masih belum hadir di jam operasional dengan berbagai alasan. Sehingga untuk menyelesaikan permasalahan ini, sistem presensi diimplementasikan agar karyawan dan dapat tertib dan melakukan pelayanan secara maksimal. Hasil dari implementasi adalah berkurangnya manipulasi data presensi.
\end{abstract}

Kata kunci-masyarakat, pendidikan, pengabdian, presensi

\begin{abstract}
In the modern era nowadays, there are still many agencies that have not maximized technology. One example of technology that has not been widely used in several agencies is the present system. Currently, there is still attendance who relies on the signature of attendance without any information about the time to come and go home. This has an impact on the performance of an agency, especially agencies that provide public services. It is not uncommon to find agencies whose employees are still not present at operational hours for various reasons. So in order to solve this problem, the present system was implemented so that employees were able to be orderly and perform services optimally. The result of the implementation reduced attendance data manipulation.
\end{abstract}

Keywords - community, dedication, education, presence

\section{PENDAHULUAN}

Istilah presensi atau kehadiran sering digunakan pada kegiatan formal atau kasual untuk mendata peserta atau pegawai (Larasatri, 2016). Umumnya pada instansi milik pemerintah atau daerah, presensi menjadi salah satu faktor untuk mengukur kinerja karyawan (Larasatri, 2016; 
Anis Fitri Nur Masruriyah, Muhammad Baharudin

Vol. 3 No 1, Februari 2021

ISSN 2657-0203

e-ISSN 2686-0244

Pangemanan, 2019; Rahmatulloh \& Gunawan, 2019). Pada Desa Bayurlor Kabupaten Karawang, presensi masih menggunakan cara tanda tangan pada buku besar. Lalu bagian kepegawaian akan melakukan pendataan untuk dilaporkan. Kelemahan pada cara ini adalah karyawan dapat memanipulasi data kehadiran dan berdampak pada kinerja dan pelayanan kepada masyarakat. Salah satu solusi untuk kelemahan metode presensi tanda tangan adalah dengan menerapkan teknologi, yaitu fingerprint.

Beberapa sumber telah membahas manfaat dan keunggulan teknologi fingerprint untuk presensi (Kristin, 2016; Larasatri, 2016; Pangemanan, 2019; Rahmatulloh \& Gunawan, 2019; Wijayanto, 2017). Kristin (2016) menjelaskan bahwa presensi menggunakan teknologi fingerprint mampu mempengaruhi secara langsung kinerja dan motivasi kerja pada guru secara positif. Selanjutnya, Larasati (2016) dan Rahmatullah dan Gunawan (2019) membuktikan implementasi presensi fingerprint mempengaruhi tingkat disiplin pegawai yang berdampak pada perubahan positif perilaku pegawai. Selain itu, presensi fingerprint tidak hanya digunakan oleh karyawan, namun juga mahasiswa dan terbukti mampu mempersingkat waktu proses pengambilan presensi dan menurunkan nilai kecurangan (Wijayanto, 2017).

Agar masalah presensi pada Kantor Desa Bayurlor dapat diatasi, Desa Bayurlor dijadikan mitra dalam kegiatan pengabdian kepada masyarakat Universitas Buana Perjuangan Karawang. Sehingga, sistem presensi yang diterapkan mampu meningkatkan disiplin kehadiran aparat desa.

\section{METODE}

Tahapan yang dilakukan pada kegiatan pengabdian dimulai dengan datang ke Desa Bayurlor untuk melihat kondisi dan menghubungi aparat desa untuk meminta izin melakukan kegiatan pegabdian kepada masyarakat. Selanjutnya mengevaluasi dan melakukan wawancara terkait angket dan keperluan desa. Kemudian mengidentifikasi hal-hal yang dapat dilakukan oleh tim pengabdian dan mitra.

\section{HASIL DAN PEMBAHASAN}

Kantor desa Bayurlor belum memiliki fasilitas presensi yang baik, padahal proses penyelenggaraan pemerintah desa dituntut untuk lebih optimal (Rahmatulloh \& Gunawan, 2019). Agar penyelenggaraan pemerintah desa dapat optimal, harus didukung dengan aktifitas kerja aparat desa yang dipengaruhi oleh presensi dan kedisiplinan terhadap jadwal dan lingkup kerja. Apabila aparat desa lalai dan kurang disiplin, hal ini akan mempengaruhi kinerja dan pelayanan terhadap masyarakat. 
Anis Fitri Nur Masruriyah, Muhammad Baharudin

Vol. 3 No 1, Februari 2021

ISSN 2657-0203

e-ISSN 2686-0244

Presensi fingerprint diusulkan karena memiliki kelebihan dibandingkan presensi secara tradisional (tanda tangan). Beberapa kelebihan presensi fingerprint adalah meminimalisir kecurangan presensi. Presensi yang dilakukan secara tradisional dapat dimanipulasi waktunya dan pelakunya. Kemungkinan terburuk adalah aparat memalsukan tanda tangan. Hal ini tentu berpengaruh pada peforma kinerja desa, karena oknum yang harusnya menyelesaikan pekerjaan tidak hadir dan belum tentu ada penggannti. Sehingga, masalah kecurangan presensi dapat diselesaikan dengan presensi fingerprint.

Selanjutnya keunggulan presensi fingerprint dapat mengurangi waktu dalam melakukan rekapitulasi presensi. Pada presensi tradisional, rekapitulasi dilakukan setiap hari dan akan dilakukan perincian setiap bulannya untuk mengetahui kehadiran setiap aparatur yang bekerja pada desa. Namun, dengan presensi fingerprint rekapitulasi dapat dilakukan sewaktu-waktu sehingga mengemat waktu dan tenaga. Pada Tabel 1 disajikan perbandingan presensi tradisional dan presensi fingerprint (Ilmiana et al., 2016).

Tabel 1 Perbandingan Presensi Tradisional dan Fingerprint

\begin{tabular}{lcc}
\hline & Tradisional & Fingerprint \\
\hline Hemat Kertas & Tidak & Iya \\
Praktis & Tidak & Iya \\
Kecurangan & Iya & Tidak \\
Aman & Tidak & Iya \\
Murah & Iya & Tidak \\
Pengolahan data mudah & Tidak & Iya \\
\hline
\end{tabular}

Berdasarkan Tabel 1, dapat disimpulkan bahwa presensi fingerprint memiliki lebih banyak keunggulan dibanding presensi tradisional. Proses pemasangan presensi fingerprint juga sederhana dan ditunjukkan pada Gambar 1. Perangkat yang diperlukan adalah mesin presensi, kabel Unshield Twisted Pair (UTP) untuk menghubungkan komputer dengan perangkat lain. Kemudian $H U B /$ Switch sebagai media untuk menghubungkan computer dengan mesin presensi.

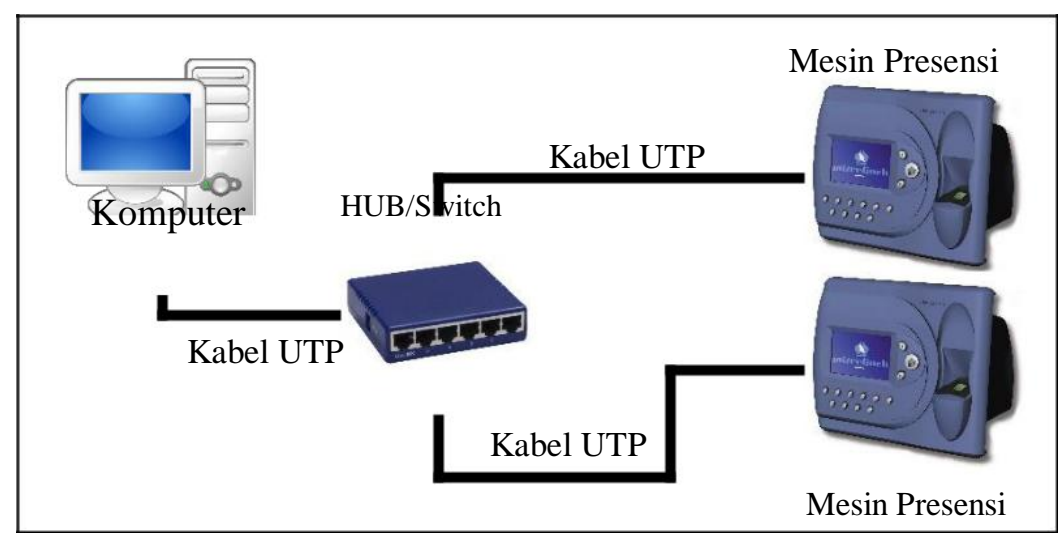

Gambar 1 Proses Pemasangan Mesin Presensi Fingerprint 


\section{KESIMPULAN DAN SARAN}

Pada kantor Desa Bayurlor belum ada pemanfaatan teknologi untuk mencatat presensi aparatur desa. Sehingga dibuat gagasan untuk memanfaatkan teknologi presensi fingerprint untuk meningkatkan disiplin dan motivasi kerja aparatur desa. Memanfaatkan teknologi dapat meningkatkan kepuasan masyarakat dalam pelayanan dan berpengaruh pada kinerja aparatur desa. Gagasan yang diimplementasikan dimulai dengan menghubungi aparatur Desa Bayurlor untuk meminta izin melakukan sosialisasi dan mengadakan kegiatan pengabdian masyarakat untuk melakukan penyuluhan dan uji coba alat.

Tindak lanjut implementasi dilakukan berkala dan dapat dikembangkan lebih baik, seperti memantau kehadiran menggunakan telepon seluler. Sehingga pemantauan kehadiran dapat diperiksa secara berkala dan realtime.

\section{DAFTAR PUSTAKA}

Ilmiana, Z., Syaharudin, \& Suhartini, E. (2016). Analisis Perbandingan Penerapan Sistem Absensi Manual dan Fingerprint Terhadap Disiplin Pegawai Negeri Sipil di Kantor Dinas Perindustrian dan Perdagangan Kabupaten Gowa (Issue June).

Kristin, L. S. (2016). Pengaruh Penerapan Presensi Sidik Jari (Fingerprint) Terhadap Kinerja Guru Melalui Motivasi Kerja di SMA Negeri 5 Malang. Journalmanagement, 12(3A), 170-177.

Larasatri. (2016). Korelasi Implementasi Sistem Presensi Sidik Jari (Fingerprint) Online dan Kedisiplinan Terhadap Perubahan Perilaku Kerja Pegawai. 4(1), 1-20.

Pangemanan, S. (2019). Evaluasi Kebijakan Disiplin Pegawai Negeri Sipil Melalui Presensi Sistem Sidik Jari. 3, 1-10.

Rahmatulloh, A., \& Gunawan, R. (2019). Sistem Presensi Berbasis Sidik Jari untuk Peningkatan Disiplin Kehadiran Aparat Desa. JATI EMAS (Jurnal Aplikasi Teknik Dan Pengabdian Masyarakat), 3(1), 14. https://doi.org/10.36339/je.v3i1.183

Wijayanto, E. (2017). Sistem Presensi Mahasiswa Dengan Fingerprint. Naskah Pubilkasi Universitas Muhammadiyah Surakarta, 13(September), 41-56. 